\title{
Prostate Cancer Promotes CD11b Positive Cells to Differentiate Into Osteoclasts
}

\author{
Kosuke Mizutani, ${ }^{1}$ Sudha Sud,${ }^{1}$ and Kenneth J Pienta ${ }^{1,2 *}$ \\ ${ }^{1}$ Departments of Internal Medicine and Urology, University of Michigan School of Medicine, \\ 7303 CCC 1500 E. Medical Center Drive, Ann Arbor, Michigan 48109-5946 \\ ${ }^{2}$ University of Michigan Comprehensive Cancer Center, 7303 CCC 1500 E. Medical Center Drive, Ann Arbor, \\ Michigan 48109-5946
}

\begin{abstract}
Bone is the preferred site of prostate cancer metastasis, contributing to the morbidity and mortality of this disease. A key step in the successful establishment of prostate cancer bone metastases is activation of osteoclasts with subsequent bone resorption causing the release of several growth factors from the bone matrix. $\mathrm{CD} 11 \mathrm{~b}+$ cells in bone marrow are enriched for osteoclast precursors. Conditioned media from prostate cancer PC-3 cells induces CD11b+ cells from human peripheral blood to differentiate into functional osteoclasts with subsequent bone resorption. Analysis of PC-3 conditioned media revealed high amounts of IL- 6 and IL-8. CD11b+ cells were cultured with M-CSF and RANKL, IL-6, IL-8, and CCL2, alone or in combination. All of these conditions induced osteoclast fusion, but cells cultured with M-CSF, IL-6, IL-8, and CCL2 were capable of limited bone resorption. Co-incubation with IL-6 and IL-8 and the RANK inhibitor, RANK-Fc, failed to inhibit osteoclast fusion and bone resorption, suggesting a potential RANKL-independent mechanism of functional osteoclast formation. This study demonstrates that functional osteoclasts can be derived from CD11b + cells derived from human PBMCs. Prostate cancer cells secrete factors, including IL-6 and IL-8, that play an important role in osteoclast fusion by a RANKL-independent mechanism. J. Cell. Biochem. 106: 563-569, 2009. (c) 2009 Wiley-Liss, Inc.
\end{abstract}

KEY WORDS: OSTEOCLAST; CD11B; PROSTATE CANCER; RANKL; IL-6; IL-8; CCL2

$\mathrm{P}$

rostate cancer is the most commonly diagnosed malignancy in US men [Walczak and Carducci, 2007]. Advanced prostate cancer is first treated through chemical or surgical castration because a large percentage of the cancer cells are androgen dependent. The large majority of patients, however, relapse within a few years of treatment because of the emergence of a castration resistant clone of cancer cells. Castration independent prostate cancer is an incurable disease with little effective therapy and there is a great need for novel therapeutic strategies that target the molecular basis of castration-independent, chemo-resistant prostate cancer [Isaacs, 2005]. Previous studies have demonstrated that $83-90 \%$ of men had evidence of bone metastasis when they died of prostate cancer [Loberg et al., 2005; Keller et al., 2007; Kingsley et al., 2007]. Bone is the preferred metastasis site of advanced prostate cancer, and in many patients, the only clinically evident site of metastasis at the time of death [Taichman et al., 2007]. There is a great need of novel therapeutic strategies that target the molecular basis of advanced prostate cancer-bone interactions. A key step in the successful establishment of prostate cancer bone metastases is osteoclast formation and bone resorption followed by the release of several growth factors from the bone matrix that promotes tumor growth [Taichman et al., 2007]. The mechanisms by which prostate cancer cells promote osteoclast formation and bone resorption remain unclear.

Previous reports suggested that RANKL, Interleukin-6 (IL-6), Interleukin-8 (IL-8), and C-C chemokine ligand 2 (MCP-1, CCL2) mediate osteoclast formation from human bone marrow mononuclear cells (HBMCs) and human peripheral blood mononuclear cells [Kudo et al., 2003; Lu et al., 2007]. Furthermore, prostate cancer cells have been demonstrated to secrete these factors that promote osteoclastogenesis of HBMCs [Lu et al., 2007]. The purpose of this study was to further delineate the cell-types and mechanisms involved in prostate cancer induced osteoclastogenesis.

Grant sponsor: NIH; Grant number: P01 CA093900; Grant sponsor: American Cancer Society Clinical Research Professorship; Grant sponsor: NIH SPORE in prostate cancer; Grant number: P50 CA69568; Grant sponsor: Cancer Center; Grant number: P30 CA46592; Grant sponsor: SouthWest Oncology Group; Grant number: CA32102; Grant sponsor: Prostate Cancer Foundation.

*Correspondence to: Dr. Kenneth J Pienta, MD, 1500 E. Medical Center Drive 7303 CCC, Ann Arbor, MI 48109-5946. E-mail: kpienta@umich.edu

Received 18 November 2008; Accepted 19 November 2008 • DOI 10.1002/jcb.22021 • 2009 Wiley-Liss, Inc.

Published online 23 January 2009 in Wiley InterScience (www.interscience.wiley.com). 
Monocyte-macrophages are known to be the precursors of osteoclasts [Fujikawa et al., 1996; Quinn et al., 1998]. The cell surface antigen $\mathrm{CD} 11 / \mathrm{CD} 18$ is known to be a heterodimeric structure, consisting of a common $\beta$ subunit (CD18) and a distinct $\alpha$ subunit (CD11a, CD11b, CD11c). CD11b/CD18 is also known as Mac-1/C R3, and $\alpha_{M} \beta_{2}$-integrin and is expressed in human monocytes, macrophages, neutrophils, and eosinophils [Murdoch et al., 2008]. Hayashi et al. [2008] demonstrated that CD11/CD18 is required for nuclear factor- $\kappa \mathrm{B}$ ligand (RANKL)-induced osteoclast differentiation.

RANKL induces osteoclast formation and activation in the presence of macrophage colony stimulating factor (M-CSF) through NFATc-1 and MMP9 activation [Takayanagi, 2005; Boyce and Xing, 2008; Del Fattore et al., 2008]. Furthermore, IL-6 and IL-8 are known to be highly expressed in prostate cancer metastatic sites [Lu et al., 2007]. CCL2 is a member of the CC beta chemokine family and is classically known for activating chemotaxis for monocyte/macrophages and other inflammatory cells via its receptor CCR2. The precise mechanism underlying the role of CCL2 on osteoclast formation remains to be explored.

In this study, human recombinant chemokines were used to identify which factors were important in osteoclast formation and bone resorption from human peripheral mononuclear CD11b+ cells.

\section{MATERIALS AND METHODS}

\section{REAGENTS}

Recombinant human M-CSF, IL-6, IL-8 and neutralizing antibodies for IL-6 and IL-8 and RANKFc were purchased from R\&D systems (Minneapolis, MN). RANKL and rhMCP-1 were purchased from PEPROTECH, Inc. (Rocky Hill, NJ) and APOLLO (Alexandria, Sydney, Australia), respectively.

\section{CELL CULTURE}

Human prostate cancer PC-3 cells were cultured in RPMI 1640 (GIBCO) supplemented with 10\% fetal bovine serum (GIBCO) under a humidified atmosphere of $5 \% \mathrm{CO}_{2}$ at $37^{\circ} \mathrm{C}$. For preparing conditioned media to induce osteoclasts, PC-3 cells were cultured in $150 \mathrm{~mm}^{2}$ tissue culture flasks to $90 \%$ confluency. Cells were then washed with PBS and cultured with 1\% serum media for $48 \mathrm{~h}$. The conditioned media was normalized for cell number $\left(1.0 \times 10^{6}\right.$ cells/ $\mathrm{ml}$ ). The conditioned media was centrifuged and supernatant was collected and stored in $-20^{\circ} \mathrm{C}$ until use.

\section{CYTOKINE ARRAY}

Cytokine arrays were purchased from R\&D systems and used per manufacturer's instructions. Briefly, after blocking, membranes were incubated overnight with $1 \mathrm{ml}$ of the conditioned medium collected from PC-3 cells. Membranes were then washed and immunoreactive spots were detected with chemiluminescence.

\section{ELISA ASSAYS}

ELISA analysis for IL-6, IL-8, and CCL2 (R\&D systems) were performed following the manufacture's instructions. ELISA analysis kit for RANKL was purchased from Biomedica Medizinprodukte $\mathrm{GmbH} \&$ Co., KG (Austria).

\section{QUANTITATIVE RT-PCR}

RNA was extracted according to manufacturer's instructions by using RNAeasy Micro Kit (Qiagen, Inc., USA). Briefly, cells were lysed directly in the wells and homogenized by passing through a needle several times. RNA was precipitated with 70\% ethanol and applied to RNAeasy MiniElute columns. Columns were washed with buffers and 80\% ethanol. Total RNA was eluted from the columns with RNAase-free distilled water. One microgram of total RNA of each sample was reverse transcribed by using High Capacity cDNA Reverse Transcription Kit (Applied Biosystems, Branchburg, NJ). Primers (NFATc-1, MMP9) were purchased from Applied Biosystems. The housekeeping transcript, GAPDH, was used as a control for standardization. PCR was carried out with TaqMan Universal PCR Master Mix (Applied Biosystems).

\section{OSTEOCLAST FORMATION ASSAYS}

Human peripheral mononuclear cells (PBMCs) were isolated by Ficoll-Paque (Amersham Biosciences) density gradient centrifugation from healthy male volunteers. Cells of the monocyte fraction $(\mathrm{CD} 11 \mathrm{~b}+)$ were isolated from the PBMCs by MACS CD11b Micro Beads (Miltenyi Biotec) as recommended by the manufacturer. CD11b cells $\left(5 \times 10^{5}\right)$ were seeded on coverslips (Nalge Nunc International, Rochester, NY) in MEM supplemented with 10\% fetal bovine serum, penicillin (100 U/ml), streptomycin $(100 \mathrm{mg} / \mathrm{ml})$ and M-CSF $(25 \mathrm{ng} / \mathrm{ml})$ in 24 wells. Twenty-four hours after seeding, media was changed to fresh media and incubated in the presence of M-CSF (25 ng/ml), RANKL (30 ng/ml), IL-6 (5 ng/ml), IL-8 (30 ng/ $\mathrm{ml})$, RANKFc $(1 \mu \mathrm{g} / \mathrm{ml})$ or combination of PC-3 conditioned medium and MEM (1:1) and anti-IL-6 $(0.6 \mu \mathrm{g} / \mathrm{ml})$ and anti-IL-8 antibody (1.8 $\mu \mathrm{g} / \mathrm{ml}$ ). Cells were cultured for 14 days and then fixed and stained with a TRAP staining kit (Sigma). Coverslips were also fixed in methanol and stained immunocytochemically using an antibody against vitronectin receptor (Abcam, Cambridge, MA). TRAP + cells that resembled RANKL-induced multinuclear cells were considered to be osteoclasts and counted under the microscope. Stained cell images were obtained using a BX51 microscope (Olympus, Japan).

\section{FLOW CYTOMETRY}

CD11b + cells were stained with anti-human CD11b-FITC (Pharmingen) antibodies and their matching isotype controls according to the manufacturer's protocols. The cells were incubated with antibodies for $30 \mathrm{~min}$ at $4^{\circ} \mathrm{C}$ and washed with PBS. The samples were analyzed by using a FACSCalibur flow cytometer and CellQuest software (Becton Dickinson, Bedford, MA).

\section{BONE RESORPTION ASSAYS}

CD11b + cells $\left(5 \times 10^{5}\right)$ were seeded on the resorbable artificial bone film-coated disks (Becton Dickinson) and incubated as described above. After 3 weeks of culture, cells were removed by sodium 5\% hypochlorite solution and bone resorption area images were obtained by a BX51 microscope. The mean area of resorption from five randomly selected fields was analyzed with Adobe Photoshop software (Adobe). 


\section{IDENTIFICATION OF CYTOKINES AND RANKL SECRETION BY PROSTATE CANCER, PC-3 CELLS}

The fact that conditioned medium of several prostate cancer cell lines induces osteoclast from HBMCs or the general PBMC population is well established. Prior to the osteoclast formation experiment, we investigated the population of cells isolated by CD 11b beads. More than $90 \%$ of isolated cells were CD11b positive (Fig. 1). Osteoclasts were induced from the CD11b+ fraction of PBMCs by PC-3 conditioned media (Fig. 2A). These osteoclasts were considered to be functional as evidenced by bone resorption in vitro (Fig. 2B). Identification of factors from prostate cancer cells is essential to explain the mechanism of prostate cancer induced bone resorption. A limited cytokine antibody array demonstrated that PC3 cells secrete high amounts of GM-CSF, GRO, IL-6, IL-8, IGF-BP2, TGF- $\beta 2$, TIMP-1, and TIMP-2 but very little CCL2 (Fig. $2 \mathrm{C}$ ). Of these factors, IL-6, IL-8, and CCL2 are reported to be important for osteoclast formation. To quantify these factors in PC-3 conditioned medium, the amount of IL-6, IL-8, CCL2, and RANKL by ELISA was measured. IL- 6 and IL- 8 were highly secreted in PC-3 conditioned medium; however, the level of RANKL $(<5 \mathrm{pg} / \mathrm{ml})$ and CCL2 (undetectable) were low (Fig. 2D).

\section{IL-6 AND IL-8 PROMOTE CD11b POSITIVE CELLS TO OSTEOCLAST LIKE CELL BUT NOT BONE RESORPTION}

At day 14 after incubation in the presence of each factors plus MCSF, osteoclast fusion was detected by TRAP staining and vitronectin. As shown in Figure 3A-D; IL-6, IL-8 alone and in combination induced TRAP-positive multinuclear cells from CD11b + cells. The number of IL-6 and IL-8 induced osteoclastlike cells were similar and approximately half of the number of those seen in M-CSF + RANKL stimulated conditions or in the IL- $6+$ IL-

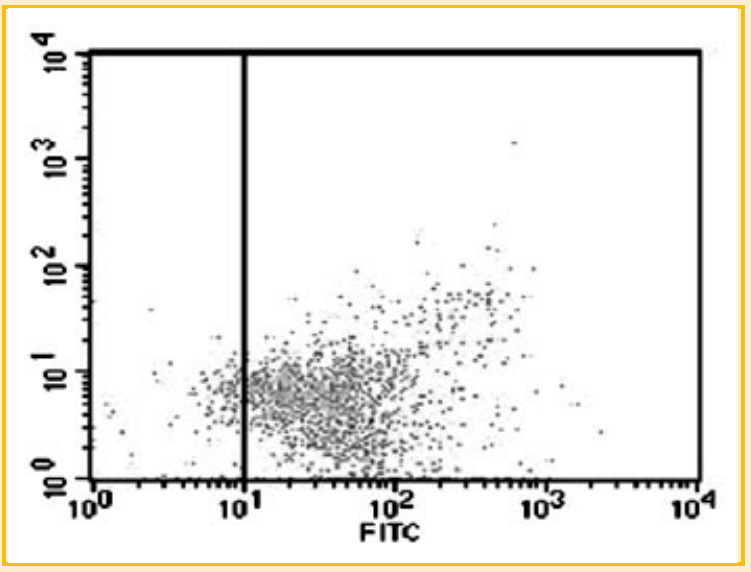

Fig. 1. Prostate cancer promotes $C D 11 b+$ cells to differentiate into osteoclasts. PC-3 conditioned media-induced osteoclast formation (A: TRAP staining, B: bone resorption) Bars; $200 \mu \mathrm{m}$. CD11 b + cells $\left(0.5 \times 10^{6}\right)$ were cultured with M-CSF ( $25 \mathrm{ng} / \mathrm{ml})$ and $50 \%$ conditioned media from PC-3 cells in 24 well plates for 14 days. C: Anti-body based cytokine analysis of PC-3 conditioned media. D: ELISA measurement of RANKL, CCL2, IL-6, and IL-8 in PC-3
$8+$ M-CSF stimulated conditions. Co-incubation with M-CSF, IL-6, IL-8, and RANKFc, a biologic inhibitor of RANKL, failed in inhibiting osteoclast fusion and bone resorption. This result implies that IL-6 and IL-8 have a potential RANKL independent mechanism of osteoclast fusion. M-CSF and CCL2 induced CD11b+ derived osteoclast fusion; however, the number of nuclei in CCL2 induced multinuclear cells was fewer compared to RANKL, IL-6, and IL-8 induced multinuclear cells (Fig. 3A-D).

To confirm the ability of $\mathrm{CD} 11 \mathrm{~b}+$ derived osteoclast-like cells were functional and capable of bone resorption, CD11b + cells were cultured on artificial bone discs. As expected, the soluble RANKL induced strongest bone resorption (Fig. 3C-E). CD11b+ cells cultured with other factors (IL-6, IL-8, CCL2, and their combination), demonstrated limited or no resorption as compared to RANKL stimulation (Fig. 3C-E). Interestingly, osteoclast-like cells that were induced by co-incubation with IL- 6 and IL- 8 made significantly less pit formation, regardless of the same amount of TRAP positive multinuclear cells compared with RANKL stimulation, perhaps suggesting that $\mathrm{CD} 11 \mathrm{~b}+$ require key factors like soluble RANKL for of bone resorption activity after formation of TRAP positive multinuclear, osteoclast-like cells (Fig. 3C,D).

\section{PC-3 CONDITIONED MEDIA PROMOTES CD11b POSITIVE CELLS TO DIFFERENTIATE TO OSTEOCLASTS}

PC-3 conditioned medium has been shown to promote HBMCs to osteoclasts [Lu et al., 2007]. CD11b+ cells from mice are known precursors of osteoclasts [Li et al., 2004]. To investigate the effect of PC -3 conditioned media on osteoclast formation, human CD11b+ cells were cultured with conditioned media. PC-3 conditioned media promoted CD $11 \mathrm{~b}+$ cells to fuse to form TRAP positive multinuclear cells and the cells had the capability of bone resorption (Fig. 4). The results from the cytokine array and osteoclast formation assay indicated that RANKL, IL-6, and IL-8 may play important roles in $\mathrm{CD} 11 \mathrm{~b}+$ osteoclast fusion and bone resorption. To determine the role of RANKL, IL-6, and IL-8 in PC-3 conditioned media induced $\mathrm{CD} 11 \mathrm{~b}+$ osteoclast formation, CD11b + cells were cultured with conditioned medium in the presence of RANK-Fc and neutralizing antibodies for IL-6 and IL-8. RANKFc and the combination of antiIL-6 and anti-IL-8 failed to inhibit conditioned media induced osteoclast formation (Fig. 4). To verify that prostate cancer cells induced osteoclast differentiated from $\mathrm{CD} 11 \mathrm{~b}+$ cells, bone resorption area was observed (Fig. 4A). The resorption was qualitatively different than the resorption demonstrated by stimulation with MCSF + RANKL (Fig. 3A). RANKFc had no effect on conditioned media induced osteoclast resorption while combination treatment of anti-IL-6 and anti-IL-8 antibodies slightly reduced PC-3 conditioned media induced bone resorption. These results imply that IL-6 and IL-8 may have a role in CD11b + osteoclastogenesis.

\section{EXPRESSION OF NFATC-1 AND MMP-9 BY EACH SIMULATION}

NFATc-1 and MMP-9 are known to be activated during osteoclast fusion and function [Takayanagi, 2005; Kim et al., 2006; Boyce and Xing, 2008; Del Fattore et al., 2008]. Osteoclast-related gene expression after 21 days incubation of CD11b + cells with each factor was examined by quantitative RT-PCR. Both NFAT-c-1 and MMP-9 expression were increased by RANKL compared to MCSF 


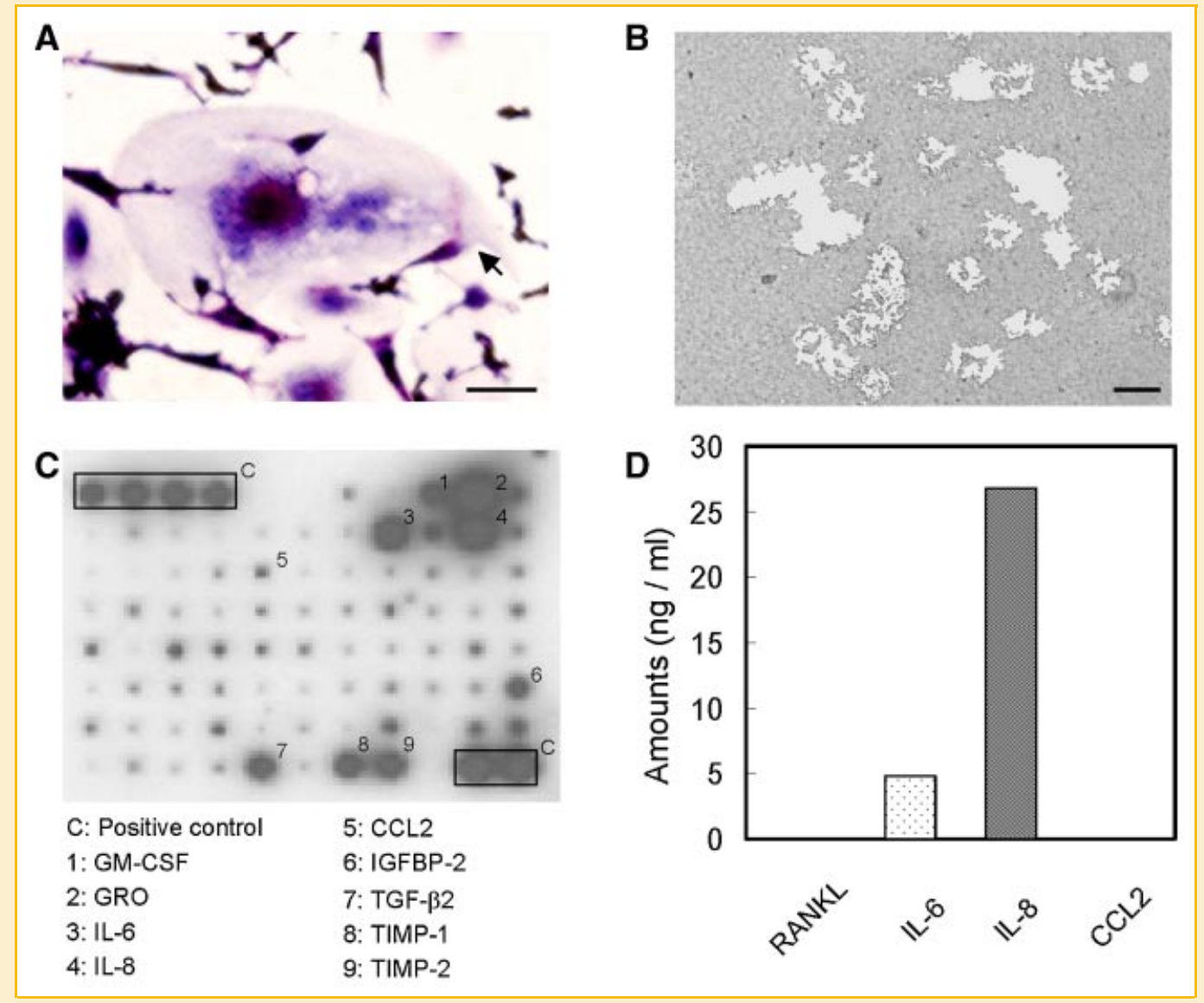

Fig. 2. Cell population analysis of isolated cells from PBMCs. Eighty to $95 \%$ of isolated cells using CD $11 \mathrm{~b}$ beads were CD $11 \mathrm{~b}$ positive. Isolated cells were incubated anti-human CD11b antibody that was conjugated with FITC and analyzed by flow cytometry.

alone (Fig. 5). Expression levels induced by other factors did not show significant difference. Interestingly, expression levels of NFaTc-1 decreased to $63 \%$ as compared to control (MCSF) conditioned media.

\section{DISCUSSION}

The results of the present study demonstrated that functional osteoclasts can be induced to be differentiated from human peripheral blood derived $\mathrm{CD} 11 \mathrm{~b}+$ cells. Recently, it is reported that reduction of activity of $\mathrm{CD} 11 \mathrm{~b}$ by siRNA and neutralizing antibody inhibited CD11b + mononuclear cells osteoclastogenesis by M-CSF and RANKL [Hayashi et al., 2008]. Hence, CD11b+ is thought to be a marker of osteoclast precursors. Detailed studies of prostate cancer induced CD11b positive cell-osteoclastogenensis have not been reported. Results demonstrated that RANKL, IL-6, and IL-8 promote osteoclast fusion from CD11b + cells. RANKL has been previously demonstrated to promote osteoclastogenesis through the up-regulation of NFATc-1 in HMBCs and PBMCs [Takayanagi, 2005; Lu et al., 2007; Boyce and Xing, 2008; Del Fattore et al., 2008]. This study extends these results and demonstrated that RANKL plays an important role in both osteoclast fusion and bone resorption of human $\mathrm{CD} 11 \mathrm{~b}+$ cells with up-regulation of NFATc-1.

IL-6 and IL-8 are known as key factors in HBMC and PBMC osteoclastogenesis [Lu et al., 2007]. Kudo et al. [2003] had reported that IL-6 induced osteoclast formation by a RANKL independent mechanism. In this study, IL-6, IL-8, and CCL2 did not induce RANKL expression from CD11b+ cells (data not shown). RANKL expression is not induced by IL- 6 in human bone marrow and osteoblasts [Hofbauer et al., 1999; Han et al., 2001]. The findings demonstrate that IL-6 effects osteoclast fusion but not bone resorption, suggesting other factor(s) are necessary for bone resorption. IL-8 is also multifunctional cytokine correlating with tumor growth, chemotactic activities and osteoclastogenesis. Bendre et al. [2005] had reported IL-8 secreted by tumor cells induce osteolysis independent of the RANKL pathway. Osteoclasts without bone resorption activity has been reported [Kim et al., 2006]. TRAPpositive multinuclear cells induced by IL- 6 and IL- 8 with negative activity for bone resorption may represent a precursor stage of functional osteoclasts. The results of no induced RANKL expression by IL- 6 and IL- 8 as well as co-culture with IL-6 and IL- 8 and RANKFc may indicate that osteoclast fusion occurs by a RANKL- 


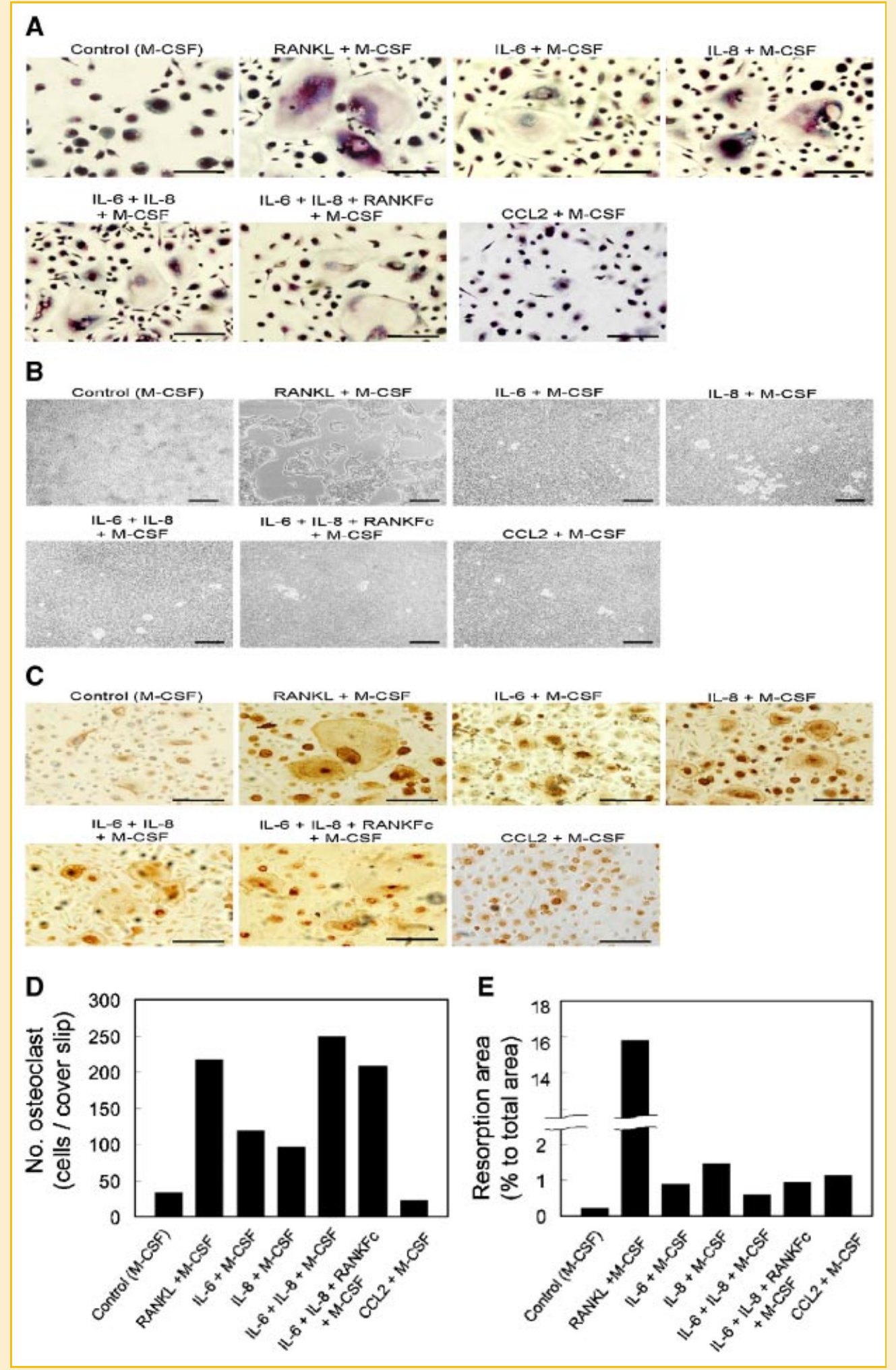

Fig. 3. Representative micrographs of TRAP positive (A) and vitronectin (B) multinuclear cells that are induced by each stimulator. CD $11 \mathrm{~b}+$ cells $\left(0.5 \times 10^{6}\right)$ were all cultured with M-CSF $(25 \mathrm{ng} / \mathrm{ml})$ and IL-6 $(5 \mathrm{ng} / \mathrm{ml})$, IL-8 (30 ng/ml), RANKFc $(1 \mu \mathrm{g} / \mathrm{ml})$ and CCL2 $(100 \mathrm{ng} / \mathrm{ml})$ or 50\% conditioned media from PC-3 cells in 24 well plates for 14 days. C: Representative micrographs of artificial bone resorption by osteoclasts. Twenty-one days after incubation with each stimulator, cells were removed and bone resorption area was visualized. Bars; $100 \mu \mathrm{m}$. Graphical representation of number of osteoclast-like multinuclear TRAP positive cells (C) and bone resorption area (D). After TRAP staining multi nucleated and expanded cells per slide were counted. The mean area of bone resorption from five randomly selected fields was quantified. 


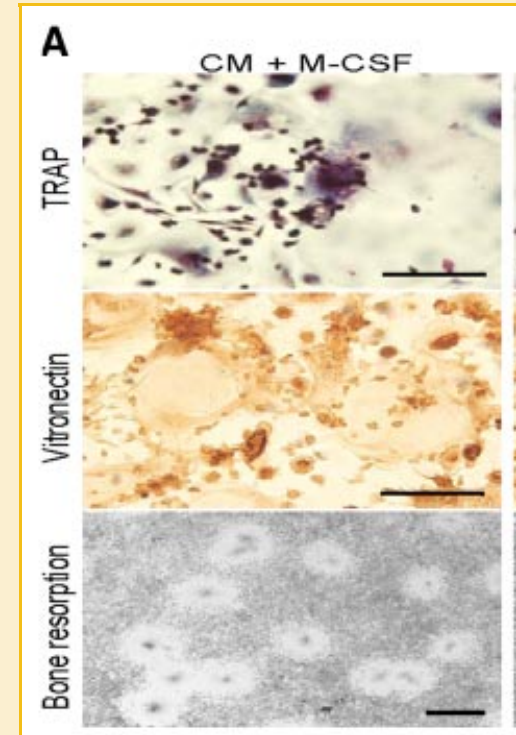

B

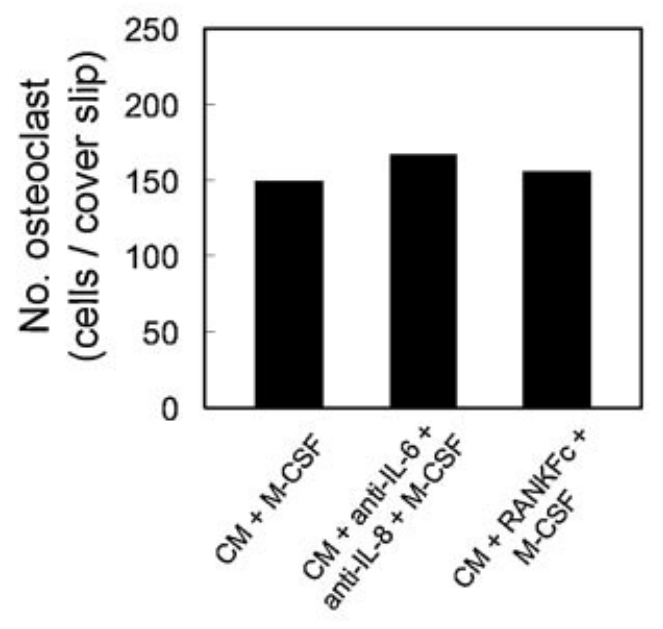

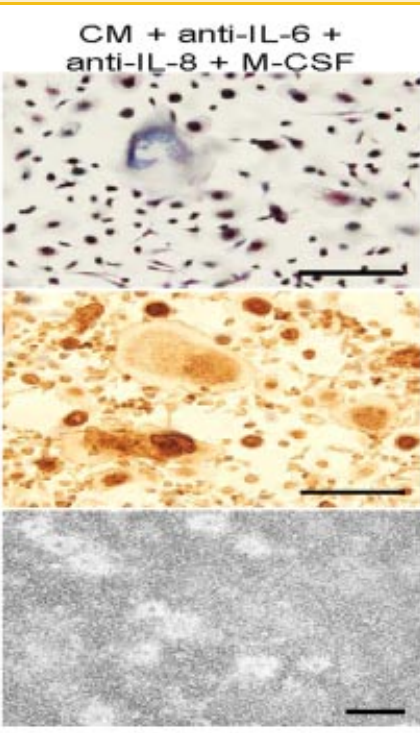

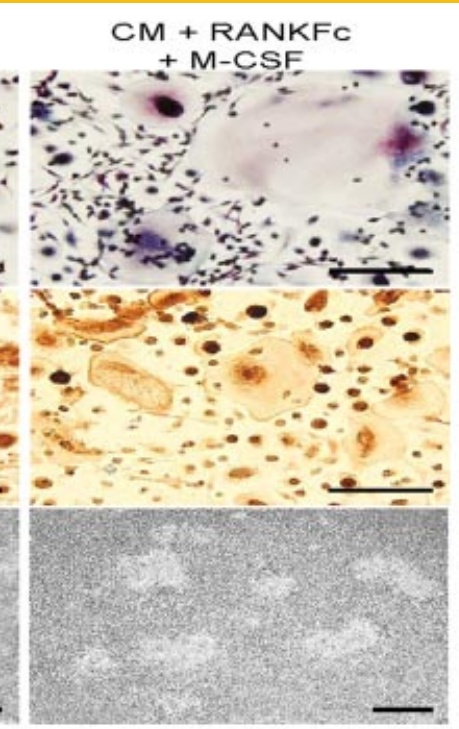

C

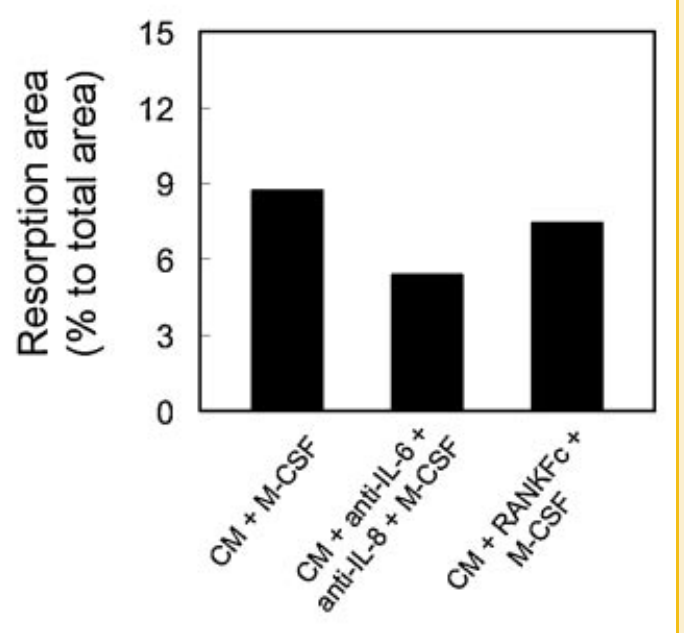

Fig. 4. A: Representative micrographs of TRAP positive (upper panels), vitronectin positive (middle panels) multinuclear cells, and bone resorption (lower panel). CD11b+cells $\left(0.5 \times 10^{6}\right)$ were all cultured with M-CSF $(25 \mathrm{ng} / \mathrm{ml})$ and neutralizing antibodies for IL-6 and IL-8 and RANKFc with $50 \%$ conditioned media from PC-3 cells. Graphical representation of number of osteoclast-like multinuclear TRAP positive cells (B) and bone resorption area (C).

independent mechanism in $\mathrm{CD} 11 \mathrm{~b}+$ cells. Direct osteoclast differentiation by IL-6 through NFATc-1 activation has been previously reported [Del Fattore et al., 2008]. Up-regulation of NFATc-1 and bone resorption by IL- 6 were not observed in this study. This may be due to the different concentrations of IL- 6 used in the different studies.

CCL2 is a member of the CC beta chemokine family and is classically known for activating chemotaxis for monocyte/macrophages and other inflammatory cells. CCL2 has been demonstrated to promote osteoclast fusion and function; however, the exact cell type that is induced to differentiate into functional osteoclasts from PBMCs remains unclear [Kim et al., 2005, 2006; Li et al., 2007; Lu et al., 2007]. These results suggest CCL2 had limited effect on both osteoclast fusion and bone resorption of $\mathrm{CD} 11 \mathrm{~b}+$ cells in vitro.

The studies conducted here confirm that conditioned medium from prostate cancer induces osteoclast formation [Lu et al., 2007]. The results demonstrate that osteoclast formation occurs via a RANKL independent mechanism. Prostate cancer induced osteoclastogenesis, however, also appears to be independent of IL- 6 and IL-8. Further experiments are needed to address the role of other factors produced by prostate cancer cells that effect osteoclast formation. For example, it has been demonstrated that PTHrP produced by prostate cancer cells can facilitate osteoclastogenesis and osteoblastogenesis [Li et al., 2007; Liao et al., 2008]. This study 


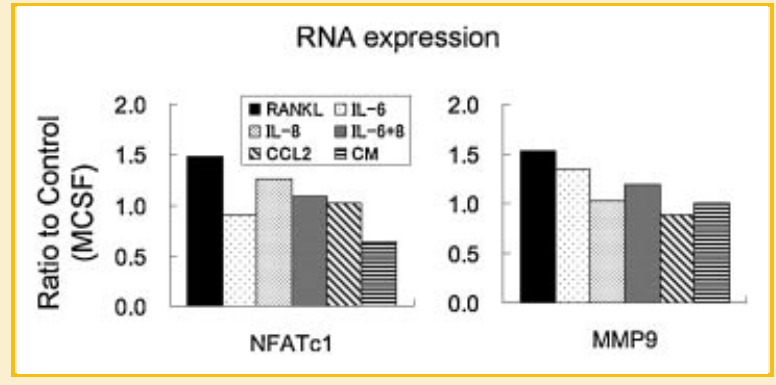

Fig. 5. Graphical representation of molecular characterization of osteoclastogenesis. Twenty-one days after incubation, mRNA was extracted and amplified. CDNA was used for quantitative real time PCR using primers of NFATC-1 and MMP9.

demonstrates that functional osteoclasts can be derived from $\mathrm{CD} 11 \mathrm{~b}+$ cells derived from human PBMCs. Prostate cancer cells secrete factors, including IL-6 and IL-8, that play an important role in osteoclast fusion by a RANKL-independent mechanism.

\section{ACKNOWLEDGMENTS}

K.J. Pienta is supported by NIH grant P01 CA093900, an American Cancer Society Clinical Research Professorship, NIH SPORE in prostate cancer grant P50 CA69568, Cancer Center support grant P30 CA46592, SouthWest Oncology Group CA32102, and the Prostate Cancer Foundation.

\section{REFERENCES}

Bendre MS, Margulies AG, Walser B, Akel NS, Bhattacharrya S, Skinner RA, Swain F, Ramani V, Mohammad KS, Wessner LL, Martinez A, Guise TA, Chirgwin JM, Gaddy D, Suva LJ. 2005. Tumor-derived interleukin-8 stimulates osteolysis independent of the receptor activator of nuclear factorkappaB ligand pathway. Cancer Res 65:11001-11009.

Boyce BF, Xing L. 2008. Functions of RANKL/RANK/OPG in bone modeling and remodeling. Arch Biochem Biophys 473:139-146.

Del Fattore A, Teti A, Rucci N. 2008. Osteoclast receptors and signaling. Arch Biochem Biophys 473:147-160.

Fujikawa Y, Quinn JM, Sabokbar A, McGee J0, Athanasou NA. 1996. The human osteoclast precursor circulates in the monocyte fraction. Endocrinology 137:4058-4060.

Han JH, Choi SJ, Kurihara N, Koide M, Oba Y, Roodman GD. 2001. Macrophage inflammatory protein-1alpha is an osteoclastogenic factor in myeloma that is independent of receptor activator of nuclear factor kappaB ligand. Blood 97:3349-3353.

Hayashi H, Nakahama K, Sato T, Tuchiya T, Asakawa Y, Maemura T, Tanaka M, Morita M, Morita I. 2008. The role of Mac-1 (CD11b/CD18) in osteoclast differentiation induced by receptor activator of nuclear factor-kappa B ligand. FEBS Lett 582:3243-3248.

Hofbauer LC, Lacey DL, Dunstan CR, Spelsberg TC, Riggs BL, Khosla S. 1999. Interleukin-1beta and tumor necrosis factor-alpha, but not interleukin-6, stimulate osteoprotegerin ligand gene expression in human osteoblastic cells. Bone 25:255-259.

Isaacs JT. 2005. New strategies for the medical treatment of prostate cancer. BJU Int 96: Suppl 2 35-40.

Keller ET, Dai J, Escara-Wilke J, Hall CL, Ignatoski K, Taichman RS, Keller J. 2007. New trends in the treatment of bone metastasis. J Cell Biochem 102:1095-1102.

Kim MS, Day CJ, Morrison NA. 2005. MCP-1 is induced by receptor activator of nuclear factor-[kappa]B ligand, promotes human osteoclast fusion, and rescues granulocyte macrophage colony-stimulating factor suppression of osteoclast formation. J Biol Chem 280:16163-16169.

Kim MS, Day CJ, Selinger CI, Magno CL, Stephens SR, Morrison NA. 2006. MCP-1-induced human osteoclast-like cells are tartrate-resistant acid phosphatase, NFATc1, and calcitonin receptor-positive but require receptor activator of NFkappaB ligand for bone resorption. J Biol Chem 281:12741285.

Kingsley LA, Fournier PG, Chirgwin JM, Guise TA. 2007. Molecular biology of bone metastasis. Mol Cancer Ther 6:2609-2617.

Kudo 0, Sabokbar A, Pocock A, Itonaga I, Fujikawa Y, Athanasou NA. 2003. Interleukin- 6 and interleukin-11 support human osteoclast formation by a RANKL-independent mechanism. Bone 32:1-7.

Li P, Schwarz EM, O'Keefe RJ, Ma L, Looney RJ, Ritchlin CT, Boyce BF, Xing L. 2004. Systemic tumor necrosis factor alpha mediates an increase in peripheral CD11bhigh osteoclast precursors in tumor necrosis factor alpha-transgenic mice. Arthritis Rheum 50:265-276.

Li X, Qin L, Bergenstock M, Bevelock LM, Novack DV, Partridge NC. 2007. Parathyroid hormone stimulates osteoblastic expression of MCP-1 to recruit and increase the fusion of pre/osteoclasts. J Biol Chem 282:33098-33106.

Liao J, Li X, Koh AJ, Berry JE, Thudi N, Rosol TJ, Pienta KJ, McCauley LK. 2008. Tumor expressed PTHrP facilitates prostate cancer-induced osteoblastic lesions. Int J Cancer 123:2267-2278.

Loberg RD, Logothetis CJ, Keller ET, Pienta KJ. 2005. Pathogenesis and treatment of prostate cancer bone metastases: Targeting the lethal phenotype. J Clin Oncol 23:8232-8241.

Lu Y, Cai Z, Xiao G, Keller ET, Mizokami A, Yao Z, Roodman GD, Zhang J. 2007. Monocyte chemotactic protein-1 mediates prostate cancer-induced bone resorption. Cancer Res 67:3646-3653.

Murdoch C, Muthana M, Coffelt SB, Lewis CE. 2008. The role of myeloid cells in the promotion of tumour angiogenesis. Nat Rev Cancer 8:618-631.

Quinn JM, Neale S, Fujikawa Y, McGee JO, Athanasou NA. 1998. Human osteoclast formation from blood monocytes, peritoneal macrophages, and bone marrow cells. Calcif Tissue Int 62:527-531.

Taichman RS, Loberg RD, Mehra R, Pienta KJ. 2007. The evolving biology and treatment of prostate cancer. J Clin Invest 117:2351-2361.

Takayanagi H. 2005. Mechanistic insight into osteoclast differentiation in osteoimmunology. J Mol Med 83:170-179.

Walczak JR, Carducci MA. 2007. Prostate cancer: A practical approach to current management of recurrent disease. Mayo Clin Proc 82:243-249. 